Organo- and Biocatalysis

\section{Key words}

keto esters cross-benzoin addition

N-heterocyclic carbenes

\title{
Dynamic Kinetic Asymmetric Cross-Benzoin Additions
}
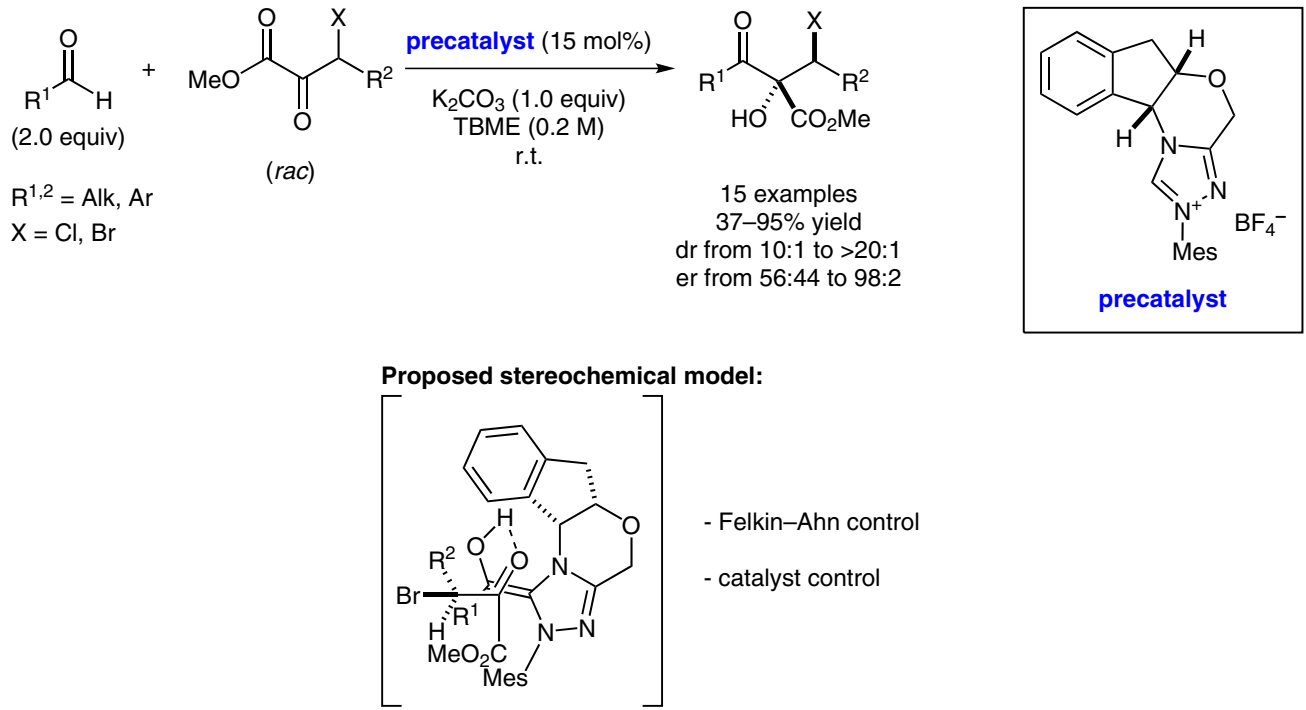

Selected examples:<smiles>CC(=O)O[C@](O)(C(=O)c1ccccc1)C(Cl)Cc1ccccc1</smiles>

95\% yield $\mathrm{dr}=13: 1$ er $=96: 4$<smiles>CC(=O)[C@](O)(C(=O)c1ccco1)C(Br)Cc1ccccc1</smiles>

$70 \%$ yield $\mathrm{dr}>20: 1$ er $=75: 25$<smiles>CC(=O)C(=O)[C@H](O)[C@H](Br)Cc1ccccc1</smiles>

$51 \%$ yield $\mathrm{dr}=14: 1$ er $=56: 44$

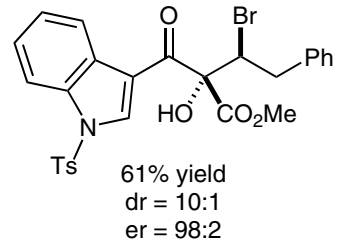

Significance: The Johnson group reports a dynamic kinetic resolution of $\beta$-halo $\alpha$-keto esters via asymmetric cross-benzoin reaction catalyzed by a chiral $\mathrm{N}$-heterocyclic carbene. This umpolung reaction adds aldehydes to racemic $\alpha$-keto esters to provide products in good yields (up to 95\% yield), good diastereoselectivities ( $d r>20: 1$ ), and excellent enantioselectivities (er up to 98:2). Furthermore, the obtained products undergo diastereoselective substrate-controlled reductions to generate highly functionalized stereotriads.
Comment: ortho-Tolualdehyde and other sterically encumbered aldehydes gave no desired transformation. Another limitation of this methodology at the current level is its requirement for aromatic aldehydes in order to obtain high enantioselectivity. Control experiments indicate irreversible benzoin formation under the applied reaction conditions. The high chemoselectivity observed is suggested to be based on the greater electrophilicity of these $\alpha$-keto esters toward the Breslow intermediate. 